\title{
ENCEPHALOPATHY FOLLOWING THE ADMINISTRATION OF STREPTOMYCIN AND PARA-AMINO-SALICYLIC ACID
}

\author{
BY
}

\author{
J. B. CAVANAGH \\ From the Bernhard Baron Institute of Pathology, the London Hospital
}

(RECEIVED FOR PUBLICATION SEPTEMBER 4, 1952)

\begin{abstract}
"Haemorrhagic encephalitis" following the administration of therapeutic substances has been frequently described and attributed to many agents, the chief of which have been the arsphenamine compounds and the sulphonamide group of drugs. In this communication the clinical and pathological findings in a patient who developed encephalopathy following the therapeutic administration of streptomycin and para-amino-salicylic acid (P.A.S.) are recorded. Two cases, probably similar in nature to the present one, have been described by Edge (1951) and Marsh (1952). Both patients recovered with residual neurological signs after a stormy course.
\end{abstract}

The pathological changes presented here indicate that the condition is essentially similar to the encephalopathy following the other drugs mentioned, while the clinical facts suggest that the lesions are the result of a hypersensitivity process.

\section{Clinical}

G. W., a male mechanic aged 22 years, was admitted on May 1, 1951, to the London Hospital Annexe, Brentwood, under the care of Dr. Kenneth Perry, having had repeated small haemoptyses over the past nine months. He gave no history of any illness or evidence of previous food or drug sensitivity. Both his father and sister probably had pulmonary tuberculosis.

Examination on admission revealed a general dryness and scaling of the skin which he stated had been present since birth. He was afebrile. Except for a diminution of respiratory movement and of percussion note over the right upper half of the chest, there were no further abnormal physical signs. A radiograph showed extensive infiltration of the right upper and mid zones of the lungs with cavitation. The sputum contained scanty acid-fast bacilli. A blood count on May 3 showed 12,000 white cells per c.mm. (51\% neutrophils, $32 \%$ lymphocytes, $8 \%$ monocytes, and $9 \%$ eosinophils; 1,080 per c.mm.). Treatment with streptomycin, $1 \mathrm{~g}$. intramuscularly daily, and para-amino-salicylic acid, 5 g. orally q.d.s., was begun on May 5.
On May 22 his temperature rose to $101^{\circ} \mathrm{F}$. Tender enlarged lymph nodes were found in the right side of the neck, and a slight erythema was noted over the face, neck, and upper chest. A blood count showed 5,000 white cells per c.mm. ( $51 \%$ neutrophils, $24 \%$ lymphocytes, $9 \%$ monocytes, $16 \%$ eosinophils ; 800 per c.mm.). A throat swab grew normal flora only. The patient had repeated rigors. The rash became generalized, was macular with slight scaling, and began to irritate, but at no time was it haemorrhagic in character. On June 1 the rash became exfoliative.

The streptomycin (total 21 g.) was stopped on May 25, the P.A.S. (total 500 g.) on June 3. On June 4 considerable oedema of the eyelids, face, and neck developed. A blood count then showed 23,400 white cells per c.mm. (51\% neutrophils, $25^{\circ}$; lymphocytes, $1 \%$ monocytes, $23 \%$ eosinophils ; 5,383 per c.mm.). On June 6 the Hess capillary fragility test was positive. The next morning the patient was found in coma with a high fever $\left(105.4^{\circ} \mathrm{F}\right.$.). All limbs were hypertonic, all reflexes were increased but equal, and the plantar responses were extensor. He responded slightly to pinprick. The general skin condition had improved considerably, but the Hess capillary test again produced a large crop of petechial haemorrhages. A blood count showed 47,800 white cells per c.mm. $(38 \%$ neutrophils, $40 \%$ lymphocytes, $4 \%$ monocytes, $18 \%$ eosinophils : 8,604 per c.mm.). The platelets appeared normal in stained blood films. Attacks of jactitation occurred involving the face and upper limbs. The temperature fell during the succeeding four days and the capillary fragility test became negative on June 11 . No diminution of platelet numbers was noted at any time in stained blood films. On June 14 albumin $(1 / 12$ vol.) and blood were detected in the urine, and continued to be present in most specimens. The blood urea rose to $398 \mathrm{mg}$. \%, and on June 18 a lumbar puncture produced clear cerebrospinal fluid containing 6 cells per c.mm. and $35 \mathrm{mg}$. \% protein. On June 21 a skin patch test with P.A.S. gave a slight erythematous reaction. The patient remained deeply comatose with occasional attacks of jactitation until death on June 22, having been unconscious for 15 days. 


\section{Pathological}

A necropsy (P.M. 242/51) was performed two days after death. The findings can be summarized as bronchopneumonia, acute haemorrhagic leuco-encephalitis, mild exfoliative dermatitis, and chronic cavitating pulmonary tuberculosis.

Brain.--In the fresh state many petechiae were seen in the white matter, and cortical petechiae were visible through the leptomeninges. After hardening in formalin coronal sections revealed numerous grey, discrete, finely granular areas (up. to $0.3 \mathrm{~cm}$. diameter) scattered throughout the white matter, and occasionally encroaching upon the grey matter. They were most numerous and occasionally haemorrhagic in the frontal and occipital lobes, were less conspicuous in the parietal lobes, and were scarcely visible in the regions of the basal ganglia. Similar grey areas were present in the white matter of the cerebellum. None was visible in the midbrain or medulla. The spinal cord was unfortunately not saved.

\section{Microscopical}

Brain.-Lesions were found referable to small blood vessels. There were areas of anaemic necrosis of irregular outline involving the cerebral cortex, especially its lower layers, and the subcortical white matter (Fig. 1). Similar irregular areas were found less frequently in the white matter. At the edge of the necroses there was an intense microglial reaction with numerous foam

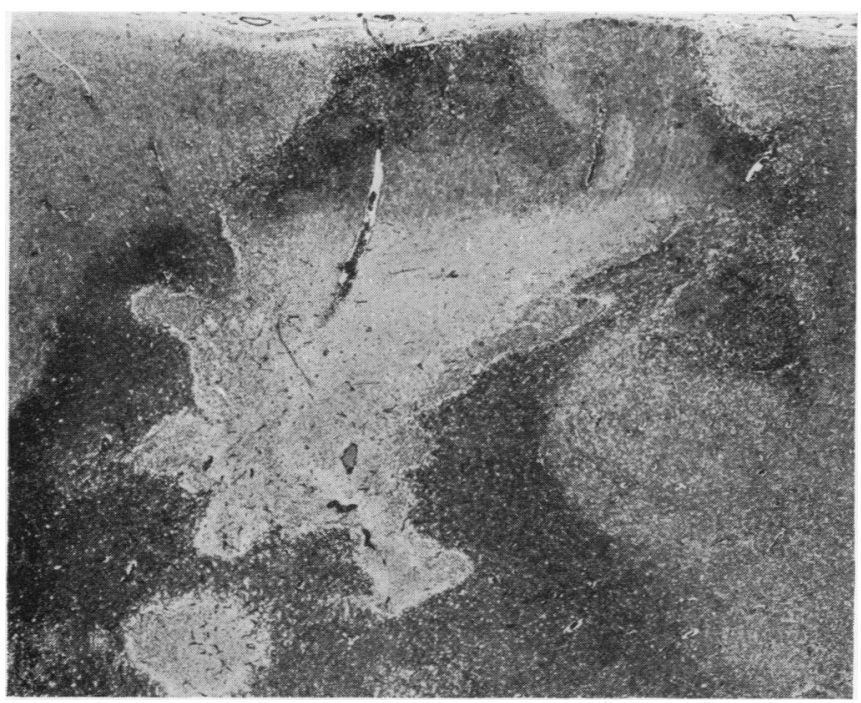

FIG. 1.-Left frontal region showing a wedge-shaped area of ischaemic necrosis reaching from the subcortical white matter through the cortex. There is a further discrete focus of demyelination below this in the white matter. $\times 7.5$. Van Gieson stain.

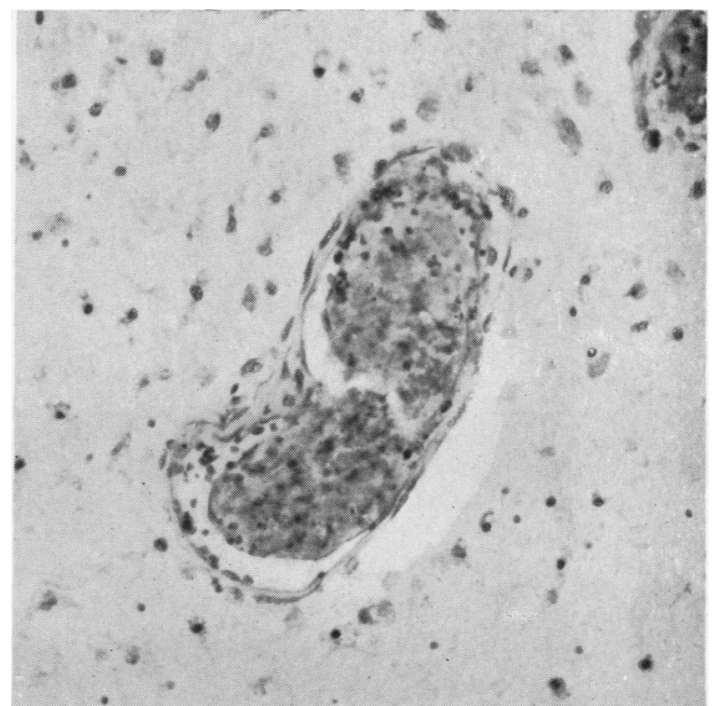

FIG. 2.-Hyaline thrombus within a small vessel from an area of necrosis. Note the thin layer of flattened cells separating it from the lumen that contains red cells, and the fragments of nuclear debris within the thrombus. $\times 190$. Giemsa stain.

cells containing sudanophil lipoid, while outside this zone were many hypertrophied fibrous astrocytes. Capillary endothelial cells had proliferated at the edges of the necrotic areas and to a lesser degree in their substance; occasional capillaries were surrounded by small haemorrhages, while others were ringed by macrophages containing granules of haemosiderin pigment. Near the necrotic areas hyaline thrombi occupied the lumina of many vessels, completely plugging the smaller but only partially filling the larger vessels. In the latter the free surface of the thrombus was covered by a simple layer of flattened endothelial cells (Fig. 2). The thrombi did not stain with special stains for fibrin or red cells. With Giemsa they showed a faint but distinct stippling on a blue background, suggesting that they were composed of conglutinated masses of platelets. Fragments of nuclear material were frequently included in the thrombus. Hyaline thrombi could not be found in any vessel in the unaffected portions of brain, nor were they present in sections taken from other organs in the body.

As well as the irregular necrotic areas perivascular zones of demyelination occupied by histiocytes and foam cells 


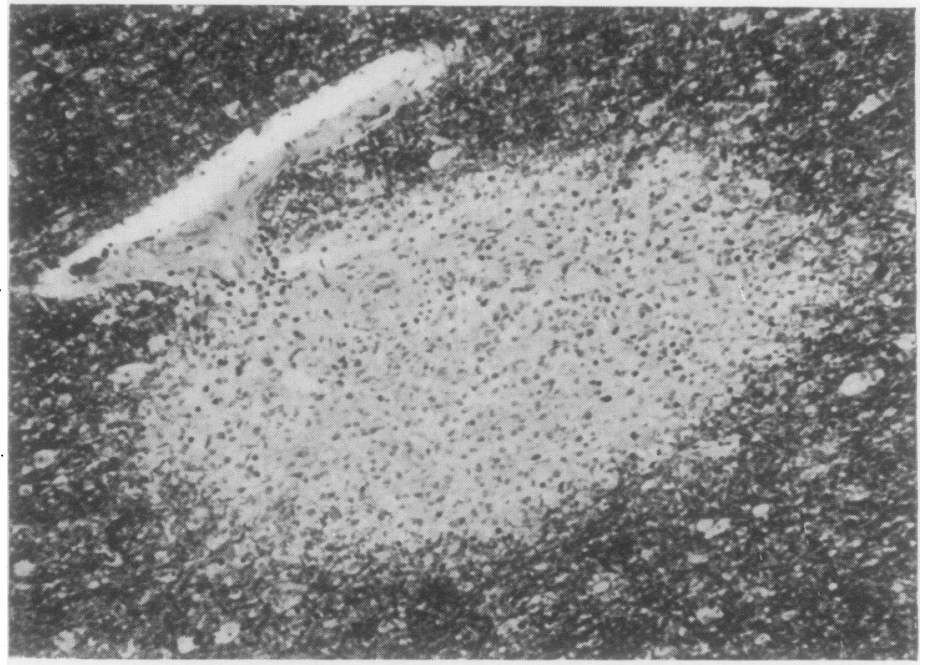

FiG. 3.-Perivascular demyelination in the white matter occupied by histiocytes. $\times 120$.

throughout the cortex. In one wedge-shaped area of recent ischaemic shrinkage the infiltration was more pronounced. The adventitia of arteries of interlobular size and their accompanying veins were infiltrated by similar cells, but their walls were otherwise unaltered. No thrombi were found.

The spleen showed changes of a chronic inflammatory nature. The pulp was infiltrated with neutrophil leucocytes and plasma cells.

The upper lobes of the lungs contained caseous and cavitatory tuberculosis, and moderately numerous acid-fast bacilli were seen in the lesions. In the lower lobes changes interpreted as early bronchopneumonia were found.

\section{Discussion}

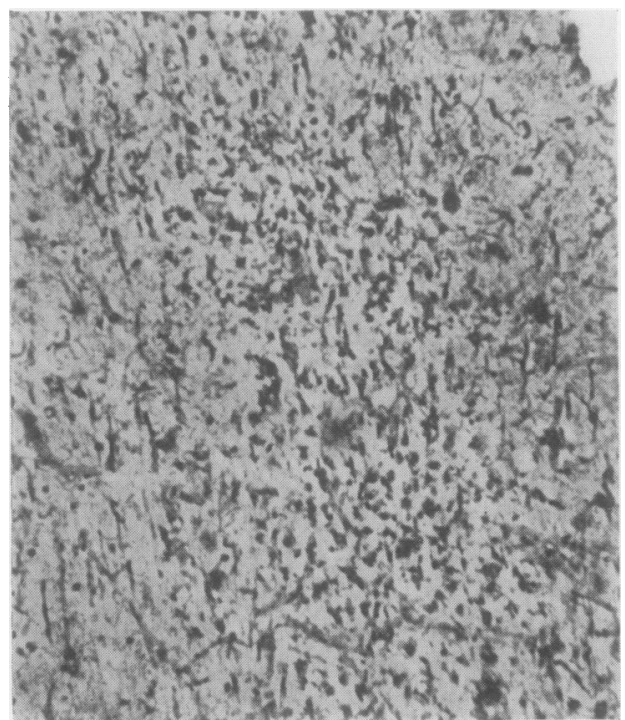

Fig. 4.-A nodule of microglia in relation to a small blood vessel in the cortex. $\times 121$. Hortega's silver carbonate.

were present in the white matter (Fig. 3). In the cortex small clusters of activated microglial cells were seen about vessels of capillary size (Fig. 4). Similar microglial clusters were present in the brain stem. No definite change was noted in the central vessels in these areas. No reactions of significance could be found in the leptomeninges in any area.

Kidney.-Diffuse but patchy infiltration by large mononuclear cells and lymphocytes occurred

The lesions in the brain that have been described here are manifestly the result of obstructive changes in small blood vessels both in the grey and in the white matter. The haemorrhagic element was partly obscured by the lateness of the process. The resemblance of these changes to those found in the encephalopathy following the administration of the sulphonamide group of drugs is striking. Extensive necroses were described in the spinal cord by Fisher and Gilmour (1939) which they attributed to vascular thrombosis. In Roseman and Aring's (1941a) case the vascular necrotic lesions were confined to the cerebral cortex. Perivascular zones of necrosis occcurred in 8 the white matter of Scheinker's case (1943). Haemorrhages were not a prominent feature in 의 these examples.

The encephalopathy due to arsphenamine medication appears to be of the same general character $N$ although the lesions are more haemorrhagic in nature. Perivascular zones of necrosis do occur 0 (Russell, 1938), although infarcts such as described $\underset{\omega}{N}$ here do not seem to have been noted. It seems reasonable, therefore, to group these drugs 0 together as agents capable of causing an encephalo- $\Phi$ pathy of the same general nature by means of ?? toxic damage to small blood vessels.

The clinical features that preceded the symptoms of cerebral catastrophe suggested that the patient $\stackrel{?}{\mathbb{Q}}$

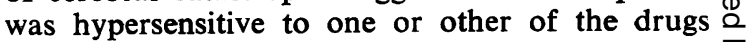
administered. Symptoms occurred after a latent $\bar{\sigma}$ period of 14 days with erythema and later with $\delta$ 
evidence of more severe capillary damage. Further changes continued to appear even after the drugs had been withdrawn, and there was a marked rise in the circulating eosinophils concomitant with the increasing severity and spread of the symptoms. Other instances have been reported in the literature of hypersensitization to streptomycin alone (Keefer, Blake, Lockwood, Long, Marshall, and Wood, 1946 ; Medical Research Council, 1950) and to P.A.S. alone (Kierland and Carr, 1949 ; Horne, 1949 ; Joules and Nassau, 1949 ; Medical Research Council, 1950 ; Cuthbert, 1950 ; Madigan, Griffiths, Lynch, Bruce, Kay, and Brownlee, 1950 ; Bridge and Hofmann, 1951 ; Gerrits, 1951 ; Steel, 1952).

Duff and Murray (1943) considered that damage to vascular endothelium was an important step in the train of events leading to clinical lesions after sulphonamides. In the encephalopathy following arsphenamines a hypersensitivity mechanism is probably at work (Russell, 1938), and in this connexion Roseman and Aring (1941b) have pointed to the significance of the necrotic vascular changes and the hyaline thrombi not uncommonly noted in this disease.

The evidence available does not allow of a decision here as to which of the two drugs was responsible. As implied in the number of references given above, P.A.S. more commonly causes hypersensitivity, and the fact that it was given for a longer period than the streptomycin rather supports its claim to have been the agent responsible. A further point of similarity between the three groups of drugs would be gained if this were so. Both P.A.S. and the sulphonamides have in their chemical structure an amino-group in the para-position, and so has an oxidation product of arsphenamines, para-amino phenylarsenoxide, that, according to Ehrlich (1914), occur's in the body. This chemical grouping is well known to confer antigenic properties to a compound. Tillett, Avery, and Goebel (1929) used p-amino glucoside and galactoside as haptenes combined with albumin and globulin to obtain anaphylaxis in experimental animals, and Landsteiner and Levine (1930) used p-amino tartranilic acid in the same way. It was the haptene in each instance and not the protein moiety that appeared to be specifically concerned in producing the hypersensitivity. A similar viewpoint has been expressed by Nitti, Bovet, and Depierre (1937) with respect to para-amino aromatic compounds and their special tendency to provoke an allergic reaction.

\section{Summary}

The clinical and pathological findings in a patient who developed encephalopathy following the administration of streptomycin and P.A.S. are described.

Hypersensitivity to one or other of the drugs is considered to be the underlying pathological process.

The relationships to sulphonamide and arsphenamine encephalopathy are briefly discussed.

I wish to thank Professor D. S. Russell for her advice in the preparation of this paper. Thanks are also due to Dr. Kenneth Perry for permission to abstract the clinical notes of his patient, and to $\mathrm{Mr}$. John King, of the photographic department, for the photomicrographs.

\section{REFERENCES}

Bridge, E. V., and Hofmann, G. N. (1951). Amer. Rev. Tuberc., 64, 682

Cuthbert, J. (1950). Lancet, 2, 209.

Duff, G. L., and Murray, E. G. D. (1943). Amer. J. med. Sci., 205, 439

Edge, J. R. (1951). Tubercle, 32, 58.

Ehrlich, P. (1914). Brit. med. J., 1, 1044

Fisher, J. H., and Gilmour, J. R. (1939). Lancet, 2, 301.

Gerrits, J. C. (1951). Acta tuberc. scand., 25, 442.

Horne, N. W. (1949). Lancet, $2,348$.

Joules, F. E., and Nassau, E. (1949). Tubercle, 30, 98.

Keefer, C. S., Blake, F. G., Lockwood, J. S., Long, P. H., Marshall, E. K., and Wood, W. B. (1946). J. Amer. med. Ass., 132, 70, Kierland, R. R., and Carr, D. T. (1949). Proc. Mayo Clin., 24, 539. Landsteiner, K., and Levine, P. (1930). J. exp. Med., 52, 347.

Medical Research Council (1950). Brit. med. J., 2, 1073.

Madigan, D. G., Griffiths, L. L., Lynch, M. J. G., Bruce, R. A., Kay, S., and Brownlee, G. (1950). Lancet, 1, 239.

Mareh, J. M. K. (1952). Ibid., 2, 606.

Nitti, F., Bovet, D., and Depierre, F. (1937). Rev. Immunol., Paris, $3,376$.

Roseman, E., and Aring, C. D. (1941 a). New Engl. J. Med., 224, 416. (1941b). Ibid., 224, 550.

Russell, D. S. (1938). J. Path. Bact., 65, 357.

Scheinker, I. M. (1943). J. Neuropath., 2, 301.

Steel, S. J. (1952). Brit. med. J., 1, 415.

Tillett, W. S., Avery, O. T., and Goebel, W. F. (1929). J. exp. Med., 50,551 . 